\section{Metabolic syndrome in elderly from a northeastern brazilian city}

\section{Abstract}

Introduction: Population aging is a global reality. In Brazil, it is so expressive and in 2050 is estimated that the number of men and women over 80 years old can overcome the $20-24$ years old population and also children under 14 years old. Metabolic syndrome is defined as a set of cardiovascular risk factors, detection and intervention in this age group may decrease cardiovascular mortality. We aimed to estimate the prevalence of metabolic syndrome (MS) in elderly patients in a northeastern Brazilian city.

Method: This is a quantitative, observational, cross-sectional and population-based study. The population consisted of non-institutionalized individuals aged $>60$ years old, attendedin the Family Health Strategy (FHS) and residents in Cajazeiras, PB, Brazil. For the diagnosis of metabolic syndrome we considered the criteria recommended by the International Federation of Diabetes.

Results: We studied 351 elderly patients with $72.4+8.7$ years old and $66.1 \%$ were female. The prevalence of MS was $69.8 \%$ and the most frequent criterion was increased waist circumference (82.6\%), followed by high triglycerides (81.5\%) and low HDL-cholesterol (80.6\%). We observed a statistically significant positive association between MS and women [OR: 1.38 (95\% Cl: 1.18 to 1.63)] and housing in urban areas [OR: 1.23 (1.02 to 1.48)].

Conclusion: There is a high prevalence of MS among the elderly mainly in women and those living in urban areas.
Betânia Maria Pereira dos Santos*1,

Carla Daltro²,

Maria do Carmo Andrade

Duarte de Farias ${ }^{1}$,

Luiz Carlos de Abreu³, Vitor

E. Valenti ${ }^{4}$,

Italla Maria Pinheiro Bezerra,

Michele Thaís S. Alves ${ }^{4}$,

Viviani Barnabé5,

Rodrigo Daminello

Raimundo 3,5,

Leila Maria Batista Araújo

1 Academic Unit, Federal University of Campina Grande, UFCG, PB, Brazil.

2 School of Nutrition, Federal University of Bahia, UFBA, Salvador, BA, Brazil.

3 Scientific Writing Laboratory, Faculty of Medicine of $A B C$, Santo Andre, SP, Brazil.

4 Center for the Study of Autonomic Nervous System (CESNA), Department of Speech Pathology, Faculty of Sciences, UNESP, Marília, SP, Brazil.

5 Department of Environmental Health, Harvard Medical School of Public Health, Boston, MA, EUA.

\section{Contact information:}

Rodrigo Daminello Raimundo

झ rodaminello@yahoo.com.br

Keywords

Metabolic Syndrome; Prevalence; Elderly 


\section{Introduction}

Population aging is a global reality. In Brazil, ten years ago the elderly accounted for a number of 14.5 million (8\% of total population). In 2020 it is estimated it to double to 26.3 million [1]. Currently, there are 18 million people over 60 years old, representing $12 \%$ of the Brazilian population. According to the World Health Organization (WHO), by 2050 the number of men and women over 80 old can overcome the children, adolescents and young adults [2].

Brazil presents in its demographic transition, rapid growth of the elderly population, associated with changes in health indicators, in particular the decline in fertility, mortality and increased life expectancy [3].

Human aging is a natural process, changes observed during this process and its consequent vulnerability to disease can be considered predictors signs of developing cardiovascular diseases, causing high mortality. Among these diseases, metabolic syndrome (MS) was described initially by Reaven as $X$ Syndrome, aiming to describe a set of metabolic and hemodynamic abnormalities, often in the obese person and that made the patient predisposed to cardiovascular diseases [4]. It was later defined as cluster of cardiovascular risk factors usually related to central fat deposition and insulin resistance [5].

The poor health of the elderly due to the difficulties to access to adequate health care and the risks of developing cardiovascular diseases are responsible for serious problems in this population. We highlight the importance of public policies and systems of surveillance of cardiovascular risk factors that are often victims of neglect in public health country investment [6].

Recognition of MS advance as a great possibility of intervention of several risk factors that threaten the health of the elderly. It may contribute to the targeting of efforts in regard to conduct effective and efficient actions and thus to enjoy a satisfactory longer life [7]. Therefore, it is necessary to periodically investigate the elderly in order to detect health problems and risk factors related to cardiovascular disease. In this context, we aimed to estimate the prevalence of MS in elderly residents in a northeastern Brazilian city.

\section{Method}

This is an observational quantitative and transverse study, using descriptive and analytical basis. The study population consisted of individuals aged $\geq$ 60 years old, non-institutionalized, attended in the Family Health Strategy (FHS) and residents in Cajazeiras, PB. Through the Primary Care Information System (SIAB) we accessed the number of seniors enrolled in the FHS, with a total of 10,050 . The power sample analysis provided a number of 351 subjects based on the total population.

Cajazeiras, PB issituated in Paraiba state, it presents a semi-arid climate, lies the metropolis João Pessoa, $480 \mathrm{~km}$, with a population of 58,446 inhabitants, 47,501 in urban areas and 10,945 in rural areas, consisting of 27,930 men and 30,507 women [8].

The survey sample was determined randomly allocated by lottery in which 371 elderly joined SIAB and the sampling plan selected was performed with SPSS (version 18.0).

Inclusion criteria considered elderly aged $\geq 60$ years, both sexes, non-institutionalized, attended by the FHS and that agreed to participate in the study and signed an informed consent letter. Older subjects with hearing loss or inability to communicate verbally were not investigated.

\section{Routine Data Collection}

Data collection was carried out in November 2011/ May 2012. Initially, we held a meeting with Community Health Workers - ACS Cajazeiras, nursing students and students of technical Nursing course 
from our Institution, dissemination of research and training. Subsequently, the ACS and the elderly students reported on the visit of the researcher to develop it by their consent. Then we conducted home visits for signing the consent form, application of socio-demographic questionnaire and anthropometric measurement.

To take the weight we used an anthropometric scale, measured by INMETRO, with the elderly situated in the center of the platform, barefoot and wearing light clothing. To measure height we used inelastic tape in millimeters divided into fixed wall without footer. The individual was placed upright, barefoot, with his/her palms on his/her thighs, knees and ankles in touch, gluteus and shoulders flush to the wall and deep inspiration.

In order to perform the measurement of waist circumference, the subjects was positioned upright, used an inelastic tape, scaled in centimeters, defining measuring $0.1 \mathrm{~cm}$ in the midline between the lower edge of the rib cage and the upper edge iliac crest, whereas hip circumference was measured with tape passing on femoral trochanters, according to the statement of IDF [9].

The blood pressure measurement was performed with sphygmomanometer, previously calibrated with cuff $12 \times 23$ and for elderly obese $17 \times$ $32 \mathrm{~cm}$. Measurements were obtained in the sitting position after rest period of at least twenty minutes and with an empty bladder. Two measures with a minimum interval of one to two minutes between them were performed at least. The average of the two measurements was considered.

The blood test was scheduled in advance and conducted in the elderly own residence after twelve hours of fasting. The samples were analyzed at the Regional Hospital of Cajazeiras, PB. The levels of triglycerides, fasting glucose, HDL-cholesterol were performed in automated unit A15 (Biosistems), an automated enzymatic method and HDL-cholesterol by direct method.
MS was classified as recommended by the International Diabetes Federation - IDF9, characterized by abdominal waist circumference $\geq 90 \mathrm{~cm}$ in men and $\geq 80 \mathrm{~cm}$ in women (at least two of the following criteria was considered for MS: triglycerides $\geq 150 \mathrm{mg} / \mathrm{dl}$, HDL-cholesterol <40 for men <50 for women, systolic blood pressure $\geq 130 \mathrm{mmHg}$ and / or diastolic blood pressure $\geq 85 \mathrm{mmHg}$, and fasting glucose $\geq 100 \mathrm{mg} / \mathrm{dl}$ ). The presence of diabetes mellitus did not exclude the diagnosis of MS. The association of three or more abnormal factors confirmed the diagnosis of MS.

\section{Ethical Considerations}

The ethical aspects of research involving humans, contemplated in Resolution No. 196/1996, the National Health Council / CNS were considered. All subjects signed the informed consent form (Appendix A). The study was approved by the Ethics Committee of the University Hospital AlcidesCarneiro, Federal University of Campina Grande-PB, process number 20111509-037. Each participant received a copy of the exams and referrals according to diagnosis.

\section{Statistical Analysis}

Descriptive results for the frequencies, means, medians, standard deviations, depending on the type and distribution of the variable in question were used. Sample calculation, provided a minimum number of 371 individuals for analysis. Measures of association prevalence ratio with confidence intervals $(95 \%)$ were used. To calculate the prevalence ratio of age the sample was divided into two groups according to the median (71 years old). Linear regression was applied to evaluate association between MS and the variables analyzed. For analysis and data tabulation EXCEL program and Statistical Package for Social Sciences-SPSS (version 18.0) were used. 


\section{Results}

We selected 371 individuals,among them, 20 did not completed the study: six died, six refused to participate and eight did not accept to perform blood collection. The 351 elderly subjects were aged between 60 and 98 years old. Most of them were female, married, lived in urban areas and had complete or incomplete primary education. Most were white and monthly income up to minimum wage (Table 1).

Table 1. Sociodemographic characteristics of 351 elderly residents in the municipality of Cajazeiras, Paraíba, 2011-201.

\begin{tabular}{|c|c|c|}
\hline Particulars & Total & Results \\
\hline Age (years) ${ }^{1}$ & 351 & $72.4(8.7)$ \\
\hline Female & 351 & $232(66.1 \%)$ \\
\hline Area where you reside & 351 & \\
\hline Urban & & $276(78.6 \%)$ \\
\hline Rural & & $75(21.4 \%)$ \\
\hline Color2 & 350 & \\
\hline White & & \\
\hline Black & & $152(43.4 \%)$ \\
\hline Dun & & \\
\hline Marital Status² & 350 & $63(18.0 \%)$ \\
\hline Single & & \\
\hline Married & & $135(38.6 \%)$ \\
\hline Widower & & \\
\hline Separate & & $76(21.7 \%)$ \\
\hline Monthly Income 2 & 348 & $178(50.9 \%)$ \\
\hline No own income & & $78(22.0 \%)$ \\
\hline Up to 1 minimum wage & & $18(5.1 \%)$ \\
\hline Between 1 salaries & & $6(1.7 \%)$ \\
\hline 2 salaries & & $153(44.4 \%)$ \\
\hline More than 2 & & $139(39.9 \%)$ \\
\hline Scholarity & 351 & $50(14.4 \%)$ \\
\hline No & & $89(25.3 \%)$ \\
\hline Basic education & & $235(67.0 \%)$ \\
\hline High school & & $26(7.4 \%)$ \\
\hline Higher education & & $1(0.3 \%)$ \\
\hline 1.: Mean (standard deviation) & \multicolumn{2}{|c|}{ 2.: Loss of information } \\
\hline
\end{tabular}

We observed a prevalence of $69.8 \%$ of MS in this sample. We also noted increased waist circumference that was the highest frequency followed by hypertriglyceridemia and low HDL - cholesterol (Table 2). A small percentage of individuals practicing physical activity and walking was the most common modality (Table 2).

Table 2. Clinical characteristics of 351 elderly residents in the municipality of Cajazeiras, Paraíba, 2011-2012.

\begin{tabular}{|l|c|c|}
\hline Particulars & Total & Results \\
\hline Metabolic Syndrome & 351 & $245(69.8 \%)$ \\
\hline HAS & & $260(74.1 \%)$ \\
\hline Diabetes & $42(12.0 \%)$ \\
\hline $\begin{array}{l}\text { Fasting Glycemia } \\
\text { Altered } \geq 100 \mathrm{mg} / \mathrm{dL}^{*}\end{array}$ & $92(29.8 \%)$ \\
\hline Triglycerides $\geq 150 \mathrm{mg} / \mathrm{dl}$ & & $286(81.5 \%)$ \\
\hline Low HDL & $283(80.6 \%)$ \\
\hline Increased Abdominal Movement & & $290(82.6 \%)$ \\
\hline Physical Activity & 351 & $79(22.5 \%)$ \\
\hline Walk & & $71(89.9 \%)$ \\
\hline Other & $8(10.1 \%)$ \\
\hline Use of Alcohol & 351 & $42(12.0 \%)$ \\
\hline Smoker & 351 & $53(15.1 \%)$ \\
\hline BMI & 351 & \\
\hline Underweight & & $10(2.8 \%)$ \\
\hline Eutrophic & $166(47.3 \%)$ \\
\hline $\begin{array}{l}\text { Overweight } \\
\text { Obese }\end{array}$ & & $174(49.6 \%)$ \\
\hline Excluded diabetics & $1(0.3 \%)$ \\
\hline
\end{tabular}


Table 3 shows the association between the MS and the variables investigated in our study. Positive and significant association was found of this syndrome with female and living in an urban area. No significant association was observed with respect to age, physical activity, smoking, drinking alcohol and excess weight (overweight/obesity).

Table 3. Association between Metabolic Syndrome and sociodemographicandlifestyle habits in 351 elderly residents in the municipality of Cajazeiras, Paraíba, 2011-2012.

\begin{tabular}{|l|l|}
\hline Variable & $\begin{array}{c}\text { Prevalence ratio } \\
(95 \% \mathrm{CI})\end{array}$ \\
\hline Female & $1.38(1.18-1.63)$ \\
\hline Housing in urban area & $1.23(1.02-1.48)$ \\
\hline Age greater 71 years (median age) & $0.98(0.86-1.11)$ \\
\hline Physical activity & $1.08(0.95-1.24)$ \\
\hline Smoking & $1.03(0.86-1.24)$ \\
\hline Alcohol use & $0.93(0.75-1.15)$ \\
\hline Overweight & $0.94(0.82-1.08)$ \\
\hline
\end{tabular}

\section{Discussion}

As a main finding, this study showed high prevalence of MS in elderly and a positive significant association of this syndrome with female gender and residence in the urban area. Most seniors were female, resided in urban area, white, married and most earned up to one minimum salary ( U\$250.00) as monthly income. Regarding education, the majority had only primary education.

The prevalence of MS found in different studies has shown wide variation depending on the population and the diagnostic criteria used. There is a trend of higher prevalence of MS with the diagnosis of IDF criteria [10].The international and Brazilian literature suggest a high prevalence of MS in the general population and in elderly. Dominguez et al [11] stated that with increasing age, there is increased risk for MS, due to the trend of higher prevalence of the components of the syndrome in the elderly. Ravagliaet al [12] emphasized that the knowledge of the MS in the elderly is important for public health because of the increasing prevalence of this disorder.

Several Brazilian studies have shown high prevalence of MS, regardless of the diagnostic criteria used, as the study on MS in hypertensive patients [13], in which a correlation between anthropometric and laboratory data was performed. In that study was showed that the prevalence of MS was $71.6 \%$ and $82.4 \%$ according to the NCEP/ATP III and IDF classification, respectively. In the study of Rigoet al (14)they identified a higher prevalence of MS, $56.9 \%$, based on the IDF definition, when compared to other diagnostic criteria. In another study performed in primary health care units in São Paulo - SP, individuals aged 60-69 years old were nearly 11 times more likely to present MS $(\mathrm{OR}=10.945, \mathrm{p}<0.001)$. When compared to 15 younger subjects aged 50-59 years old, they were nearly eight times more likely to present MS (OR = 7.779, $\mathrm{p}<0.001$ )and compared to the age group of 60-69 years old it reachedalmost 11 times more likely $(O R=10.945 ; p<0.001)$ [15].

According to our study,there was higher prevalence of the syndrome in females, corroborating other studies that have identified greater prevalence in women $[14,16]$. In this regard, a previous investigation found the highest prevalence of MS in women in Novo Hamburgo- RS. This study considered a representative sample of elderly, applying the diagnostic criteria of the revised NCEP ATP III and the IDF. The latter criterion presented the greater results (63.5 \%) [14]. However, using these same criteria, the survey of American adults found a MS prevalence of $40.0 \%$ in men and $38.0 \%$ in women, indicating the possibility that other variables, not yet clarified, may influence the association between sex and MS [17]. 
In this context, we believe that there is association between metabolic syndrome and diabetic risk factors related in the population investigated. Diabetes is considered as inflammatory state, featured by enhanced lipid per oxidation products, plasma levels of reactive oxygen species, CRP and ferritin [18]. A recent study found relationship between metabolic syndrome and diabetes in Chinese population [19], supporting our hypothesis.

The metabolic abnormalities observed mainly in elderly people in this study were the high waist circumference, hypertriglyceridemia, low HDL - cholesterol. The associations of these metabolic changes are quite evident in other studies and are considered cardiovascular risk factors [20]. Confirming the data found in this study in São Luís, MA, after adjusting for risk factors for MS, based on the IDF definition, survey analysis showed that in the elderly over 60 years old there is a higher risk of MS (prevalence ratio $=4.88,2.34$ to 10.18 ) [21].

Other studies reported that increased circumference waist is associated with a higher prevalence of MS in individuals with normal weight, overweight or obese [22]. Elevation of circumference waist is probably due to increased visceral adiposity that occurs with aging [23]. MS, common in individuals with central obesity, determines increased risk for type 2 Diabetes Mellitus and cardiovascular problems [24]. Moreover, hyperglycemia, one of the MS components, was also observed in this study, as well as diabetic patients, previously diagnosed. Advancing vascular senescence, depending on the structural, enzymatic and molecular changes is recognized as one of the main predictors of insulin resistance [25].

There was a significant frequency of hypertension in the studied sample. Advanced age remains the largest known cardiovascular risk factor. Cardiovascular senescence predisposes to the development of pathological conditions associated with cardiovascular disease due to endothelial dysfunction, arterial stiffening or thickening of the intima [26].
The association of MS with cardiovascular increases mortality about 2.5 times and total mortality about 1.5 times.The literature has demonstrated the concern of the medical profession to detect the risk of developing this syndrome early so that preventive treatment more effectively can be established [27].

Early detection of obesity, hypertension, dyslipidemia and hyperglycemia offers the possibility of change in lifestyle, prevention and treatment of disease. Proper lifestyle, purchasing habits of healthy eating, performance of physical exercise, not smoking, maintaining favorable weight may reduce metabolic risk factors [28-30].

In relation to the fact that women population has more prevalence of metabolic syndrome, we raised some hypothesis. Estrogen-related receptors is a relevant regulator of energy homeostasis and it was associated with metabolic syndrome in post-menopausal women [31]. In this context, the insulin-like growth factor-1 was reported to be higher in women than in men [32], suggesting the involvement of this hormone on metabolic syndrome.

Our study presents some points to be addressed. HbA1C is absolutely an important marker to be investigated. However, unfortunately, we were not able to obtain this variable. Another limitation of our study is the absence of adiposity levels measurement, which would strength our results. 


\section{Conclusion}

There is a high prevalence of metabolic syndrome in the elderly, especially in women and those residing in urban areas. We suggest that this approach is investigated in this age group.

\section{Conflict Of Interest}

The authors declare no conflict of interest.

\section{References}

1. Parahyba MI Simões CCS. The prevalence of disability among the elderly in Brazil. Public Health Science. 2006; 11 (4): 967-74.

2. Linhares RDS, et al. Distribution of general and abdominal obesity in adults from a city in southern Brazil. Notebook Public Health vol.28 no.3 Rio de Janeiro in March 2012.

3. Figueiredo NMA; T. Tonini Gerontology: Role of the Nurse in the Aging Process. $3^{a}$ edition Sao Caetano do Sul, SP. Yendis.

4. Reaven GM. Banting lecture 1988: role of insulin resistance in human discase. Diabetes 1998; 37: 1595-1607.

5. Lunar RL. Metabolic syndrome: current concepts. Rio de Janeiro: Revinter, 2006

6. E. Braz Among the visible and invisible: social representations in daily senescent caregiver of dependent elderly [doctoral thesis]. London: School of Nursing, University of São Paulo; 2009.

7. Neri AL. Quality of life and mature age. $7^{\mathrm{a}}$ edition. Campinas: papirus, 2007

8. IBGE. Brazilian Institute of Geography and Statistics.www.ibge. gov.br/catálogosindicators. Accessed December 2010

9. Alberti KGMN, Zimmet P, Shaw J, International Diabetes Federation IDF Epidemiology Task Force Group: the metabolic syndrome-a new worldwide definition.Lancet 2005; 366: 10591062.

10. AKS Rock, AJG s B, Huttner E, Machado DC. Prevalence of metabolic syndrome in indigenous with more than 40 years in Rio Grande do Sul, Brazil. Panamsaludpública magazine. 2011: 29 (1): $41-5$

11. Domingues LJ, Barabagallo M. The cardiometabolic syndrome and sarcopenic obesity in older persons.J Cardio metabSyndr. 2007; 2 (3): 183-8.

12. Ravaglia G, Forti P, Maioli F, Bastagli L, Chiapelli M, Montesi F, et al. Metabolic syndrome: prevalence and prediction of mortality in elderly individuals. Diabetes Care. 2006; 29 (11): 2471-6.
13. Araujo LMB, Mendonça KMB. Metabolic Syndrome in HipertensivePatientes: Correlation between Anthropometric data laboratory Findings. Diabetes Care, 30, N.6, 1624-6 2007.

14. Rigo JC, Vieira JL, Dalacorte RR, Reichert CL. Prevalence of Metabolic Syndrome in an Elderly Community: Comparison between Three Diagnostic Methods. ArqBrasCardiol. 93 (2): $85-$ 91, ago, 2009

15. Piglet, MPC, Martins, IS. Prevalence and factors associated with metabolic syndrome in users of primary health care units in $\mathrm{S}$. Paulo - SP. Ver Sig Med Bras. Vol 58 no. 1 Sao Paulo. Jan. / Feb. 2012.

16. Reis P. Relationship between the number of patients, anthropometric measures and metabolic syndrome in the elderly of Porto Alegre [dissertation]. Porto Alegre. Pontifical Catholic University of Rio Grande do Sul; 2008.

17. Ford ES. Prevalence of the metabolic syndrome defined by the International Diabetes Federation Among Adults in the U.S. Diabetes care. 2005; 28(1): 2745-9.

18. Ross L, Polotsky A. Metabolic correlates of menopause: an update. Curr Opin Obstet Gyneco. 2012;24: 402-412.

19. Nakhjavani $M$, Imani $M$, Larry $M$, Aghajani-Nargesi $A$, Morteza A, Esteghamati A. Metabolic syndrome in premenopausal and postmenopausal women with type 2 diabetes: loss of protective effects of premenopausal status. J Diabetes Metab Disord. 2014;13(1): 102.

20. Salarolli LB, Barbosa GC, Mill JG, Molina MCB. Prevalence of metabolic syndrome in population-based studies. Vitoria, ES, Brazil. Brazilian Archives of Metabolic Endocrinology 2007; 51 (7): 1143-52.

21. Barbosa, JB, Silva AAM, FF Barbosa, FCM Junior, Neto, JAF, et al. Metabolic Syndrome in Cardiac Clinic. Brazilian Archives of Cardiology 2010; 94 (1): 46-54.

22. Janssen I, Katzmarzyk PT, Ross R. Bodymass index, waistcircumference, andhealthrisk. Arch Intern Med 2002; 162:2074-9.

23. Wilson PW, Kannel WB. Obesity, diabetes, and risk of cardiovascular disease in the elderly, Am J GeriatrCardiol 2002; 11(2):119-23,125.

24. KG Mendes et al. Prevalence of metabolic syndrome and its components in the menopausal transition: a systematic review. Notebook of Public Health, Rio de Janeiro, 28 (8): 1423-1497, August 2012.

25. Wilson PW, Larson MG, Castelli. Triglycerides, HDL-cholesterol and coronary artery disease: a Framingham update on their interrelations. Can J Cardiol1994; 10:5B-9B

26. Preis SR, Massaro JM, Hoffmann, U, D' Agostino, RB.; Levy, D, Robins, SJ. et al. Neck circunference as a Novel Measure of Cardio metabolic Risk: the Framingham Heart Study. J ClinEndocrinolMetab. V. 95, n.8, p.3701-3710, 2010. 
27.I Guideline of Metabolic Syndrome. Magazine Soc Bras Hipert. 2004; 7 (4): 123-60.

28. International Diabetes Federation. Belgium: The IDF Consensus worldwide definition of metabolic syndrome; 2006. [citado 22 nov 2007]. Disponível em: http://www.idf.org.

29. Brazilian Guideline for Diagnosis and Treatment of Metabolic Syndrome. Brazilian Archives of Cardiology. 2005; 84 (Suppl 1): $1-28$.

30. Grundy SM. Cardiovascular and metabolic risk factors: how can we improve outcomes in the high-risk patient? Am J Med.2007; 120 (9A): S3-S9.

31. Audet-Walsh É, Giguére V. The multiple universes of estrogenrelated receptor $\alpha$ and $\gamma$ in metabolic control and related diseases. Acta Pharmacol Sin. 2015; 36: 51-61.

32. Halldin $M$, Brismar $K$, Fahlstadius $P$, Vikström $M$, de Faire $U$, Hellénius ML. The metabolic syndrome and ECG detected left ventricular hypertrophy--influences from IGF-1 and IGF-binding protein-1. PLoS One. 2014 Dec 2; 9(12): e108872.

\section{Comment on this article:}

\section{(f) $[$ in $8+\mathbb{S}$ P}

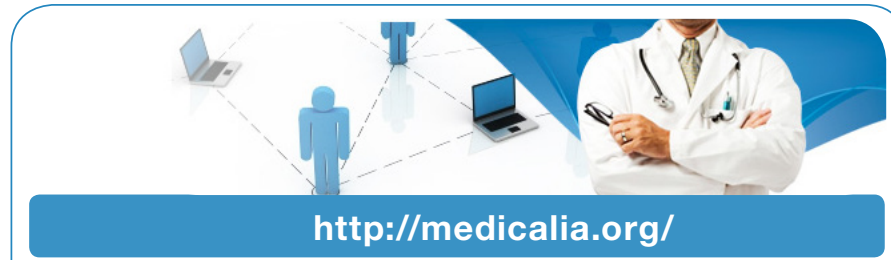

Where Doctors exchange clinical experiences, review their cases and share clinical knowledge. You can also access lots of medical publications for free. Join Now!

\section{Publish with iMedPub}

\section{http://www.imed.pub}

International Archives of Medicine is an open access journal publishing articles encompassing all aspects of medical science and clinical practice. IAM is considered a megajournal with independent sections on all areas of medicine. IAM is a really international journal with authors and board members from all around the world. The journal is widely indexed and classified Q1 in category Medicine. 